\title{
Complicated Skin and Soft-tissue Infections - Consider Gram-negative Pathogens
}

\author{
C. Ruef
}

Most infections involving the skin and adjacent soft-tissue structures are caused by gram-positive pathogens, mainly Staphylococcus aureus and group A streptococci. Empiric antibiotic treatment therefore puts a heavy emphasis on a good activity of selected antibiotics against these pathogens. However, typical regimens include some coverage against gram-negative bacteria as well. This is adequate as a sizable proportion of these infections is caused by enterobacteriaceae. The study of Chang et al. [1] in this issue of INFECTION illustrates this. The authors from Taiwan report that Klebsiella pneumoniae (16.2\% of all cases) and Escherichia coli (3.4\%) were responsible for almost one-fifth of the infections. Male sex, liver cirrhosis, malignancy and alcoholism were associated with infections by gram-negative pathogens.

The distribution of pathogens in Chang's study is quite different from distributions described in another study for three other continents, namely North America, Latin America, and Europe [2]. In Europe, E. coli accounted for $10.8 \%$ and Klebsiella sp. for $4.4 \%$ of all skin and soft-tissue infections. The corresponding rates were $7.2 \%$ and $4.2 \%$ for North America, and $14.0 \%$ and $7.0 \%$ for Latin America. Despite these differences, the studies show that gram-negative bacteria play an important role as causative agents of skin and soft-tissue infections in many areas of the world. With the observed increase in the rate of bacteria that are capable to express betalactamases with extended spectrum, clinical cure and the selection of an active antibiotic for empiric treatment might be more difficult to achieve in the future

\section{References}

1. Chang CM, Lee HC, Lee NY, Lee IW, Wu CJ, Chen PL, Lee CC, Ko NY, Ko WC: Community-acquired Klebsiella pneumoniae complicated skin and soft-tissue infections of extremities: Emphasis on cirrhotic patients and gas formation. Infection 2008; 36: 328-334.

2. Moet GJ, Jones RN, Biedenbach DJ, Stilwell MG, Fritsche TR: Contemporary causes of skin and soft tissue infections in North America, Latin America, and Europe: Report from the SENTRY antimicrobial surveillance program (1998-2004). Diagn Microbiol Infect Dis. 2007; 57: 7-13.

Infection 2008; 36: 295 DOI 10.1007/s15010-008-3408-8 Published online: July 28,2008 